\title{
A Valorização do Estrangeiro como Segregação nas Organizações
}

\author{
Fernando C. Prestes Motta \\ Rafael Alcadipani \\ Ricardo B. Bresler
}

\section{RESUMO}

A marca característica da cultura brasileira é a heterogeneidade. Além dela, alguns traços culturais despontam como marcantes em nosso país: o paternalismo, a malandragem, grande distância entre as camadas sociais e a valorização do estrangeiro. Pretendemos analisar a valorização do estrangeiro, ou melhor, o estrangeirismo, a partir de duas leituras distintas da cultura brasileira, sendo que a primeira servirá de suporte para a segunda, uma vez que são visões complementares e que se sustentam. A primeira análise e primeira parte deste ensaio foi desenvolvida por meio das figuras retóricas do colono e do colonizador apresentadas por Calligaris (1991). A segunda se dará no levantamento histórico-cultural desse traço e sua presença ao longo da formação nacional. Por fim, tentaremos argumentar que, no mundo organizacional, o estrangeirismo tem forte papel de segregação, papel este que vem sendo negligenciado nas análises do estrangeirismo no mundo organizacional.

Palavras-chaves: cultura brasileira; cultura organizacional; poder; segregação; estrangeirismo.

\begin{abstract}
The main cultural aspect of the Brazilian culture is its heterogeneity. Besides that, Brazil has other important cultural aspects such as: the paternalism; the social distance among rich and poor people; the eroticism; the Brazilian way and the high value set on foreign things - the estrangeirismo. The aim of this article is to analyse the estrangeirismo from two different readings of the Brazilian culture. The first, written by Calligaris (1991), discusses rhetoric pictures of colonist and coloniser; the second one shows historic-cultural aspects of the Brazilian culture and was written by classic authors: Caio Prado Jr., Sérgio Buarque de Holanda and Gilberto Freyre, demonstrating how this cultural aspect has been present in our country since Brazil-Colony. Moreover, we intend to discuss that the estrangeirismo may assume a feature of segregation in the organisational world.
\end{abstract}

Key words: brazilian culture; organizational culture; power; segregation. 


\title{
INTRODUÇÃO
}

\author{
"[...] Vê se me esgota, me bota na mesa \\ Que a tua holandesa, não pode esperar [...]" \\ Chico Buarque e Ruy Guerra
}

Quando falamos de Brasil, desde logo o que podemos dizer é que o traço cultural mais marcante de nosso país e a nossa principal face é a heterogeneidade. Somos, como já defendido por Ribeiro (1995), um povo claramente híbrido.

Além da patente heterogeneidade e diversidade de nossa cultura, antropólogos como Darcy Ribeiro e Roberto DaMatta, e ensaístas, sociólogos e historiadores, tais como Sérgio Buarque de Holanda, Caio Prado Jr. e Raymundo Faoro, defendem que temos alguns traços culturais marcantes como, por exemplo: a cordialidade e a preferência por relacionamentos pessoais afetivos ocasionadas por uma valorização da família-paternalista como norteadora de todas as relações sociais (Holanda, 1973); a malandragem e o jeitinho brasileiro (DaMatta, 1983); a grande distância entre as camadas sociais, ou melhor, entre "os donos do poder" e o povo (Freyre, 1963; Prado Jr., 1948; Faoro, 1976); o erotismo (Freyre, 1963); a não valorização do trabalho manual (Freyre, 1963; Hollanda, 1973); a valorização de outros países em lugar do nosso, ou melhor, o estrangeirismo (Barbosa, 1999) etc. A pergunta que resta, vendo esses traços, é se eles influenciam na gestão que se pratica em nosso país.

Guerreiro Ramos (1983) destaca que o fenômeno administrativo está sujeito ao condicionamento histórico-social. Conforme já apontado por Hofstede (1984), a cultura nacional influencia, sobremaneira, a cultura organizacional e, além disso, as estruturas organizacionais são filtradas pelo conjunto de crenças que cada um tem, deixando claro que os traços histórico-culturais de um dado país se manifestam nas organizações deste país (Prestes Motta, 1995). Assim, a compreensão de nossas características culturais é de vital importância para se poder entender o comportamento dos indivíduos nas organizações, porção organizacional em que, de fato, tais características se expressam cotidianamente.

No que diz respeito à peculiaridade brasileira, inúmeras tentativas têm sido feitas no sentido de explicitar e mostrar as relações entre a cultura nacional e as organizações locais (Barros e Patres, 1996; Borges de Freitas, 1997; Prestes Motta e Caldas, 1997), de se desenvolver uma teoria organizacional brasileira (Guerreiro Ramos, 1983; Serva, 1990) e de se verificar a influência de traços específicos de nossa cultura nas organizações locais, tais como: o paternalismo (Bresler, 
1997; Davel e Vasconcelos, 1997), a preferência pelas relações familiares (Colbari, 1995), a fixação do brasileiro na figura do estrangeiro (Caldas, 1997), o jeitinho brasileiro (Alcadipani, 1997). Além disso, análises muito interessantes vêm sendo realizadas a respeito das organizações tipicamente nacionais, como a Gaviões da Fiel (Costa, 1997), o jogo do bicho (Fischer e Santos, 1995) e um barracão de escola de samba (Vergara e Palmeira, 1997).

Neste ensaio, discutiremos a relação entre subjetividade e gestão de pessoas, ressaltando a realidade de nosso país, ou seja, como os traços culturais brasileiros podem influenciar na maneira pela qual as pessoas são percebidas, geridas, administradas e controladas.

Dentro deste contexto, nossa contribuição tentará discutir um traço históricocultural que vemos como marcante na cultura brasileira e que influencia sobremodo as organizações locais tanto em sua teoria como em sua prática e especialmente a maneira pela qual a gestão das pessoas se dá nas organizações brasileiras, qual seja, a valorização do estrangeiro, traço aliás já analisado por Caldas (1997) no mundo organizacional. Pretendemos fazer isso analisando a valorização do estrangeiro que, muitas vezes, se dá mascarada por uma pretensa busca de modernidade, a partir de duas leituras distintas da cultura brasileira. A primeira servirá de suporte para a segunda, uma vez que são visões complementares e que se sustentam.

Assim, a primeira análise e primeira parte deste ensaio foi desenvolvida por meio das figuras retóricas do colono e colonizador apresentadas por Calligaris (1991), ao passo que a segunda se dará mediante o levantamento histórico-cultural - baseada nas leituras clássicas de nossa formação e de nossa cultura que, de acordo com Cândido (1973), são as obras de Prado Jr. (1948), Freyre (1963) e Holanda (1973) - desse traço e sua presença ao longo da formação nacional. Por fim, tentaremos argumentar que no mundo organizacional em geral e na gestão de pessoas em particular o estrangeirismo tem forte papel de segregação, aspecto, aliás, freqüentemente negligenciado neste mundo. Antes, porém, gostaríamos de fazer duas considerações fundamentais.

A primeira delas é destacar que a análise de traços culturais de um dado país é uma tarefa extremamente difícil de ser realizada e ganha complexidade muito maior quando se tenta relacioná-los com a cultura das organizações, já que estamos inseridos na cultura deste país e sempre carregamos em nossas análises nossos preconceitos, nossas experiências culturais, ou seja, nossa visão de mundo e nossas convicções. Com certeza, esta análise que fazemos do topo da pirâmide social, posição que os estudiosos em geral ocupam, pode não dar conta da realidade mais importante de qualquer país: a realidade da rua. Ainda assim, buscaremos ao longo deste ensaio trazer o Brasil de verdade, tentando evitar a 
visão do antropólogo inglês, do início do século, que olhava com ares de civilizador uma tribo primitiva de aborígines australianos.

Ademais, Barbosa (1999, p. 14-15) já apontava que

"todo aquele que se aventure no empreendimento de estabelecer as ligações de culturas com diferentes formas de administrar, terá que criar seu próprio caminho. E esse caminho passa necessariamente por superar minimamente os dilemas de como enquadrar uma análise do significado, tal como a referida por Geertz - as estruturas conceituais que utilizamos para construir a experiência -, que sejam suficientemente abstratas para se constituir numa teoria, mas que, ao mesmo tempo, não se distancie demais do particular e perca o pé da realidade [...] Não é preciso nenhuma fundamentação acadêmica para afirmar que esse empreendimento é uma aventura ambiciosa, não só pela novidade que lhe é intrínseca, mas também pelo tamanho e complexidade da tarefa".

Desta forma, ficam evidentes os limites do tipo de análise que propomos, mas também a sua necessidade; em hipótese alguma podemos acovardar-nos em face de limitações tão claras.

A segunda consideração que julgamos fundamental é destacar que, para tentarmos compreender melhor qualquer traço histórico-cultural de nossa sociedade, é necessário deixar claro que a formação e a estruturação da sociedade brasileira foram marcadas pela exploração predatória dos recursos naturais locais para serem vendidos ao mercado europeu (Prado Jr., 1948; Holanda, 1973; Faoro, 1976). Os nossos grandes ciclos econômicos, da extração do pau-brasil, passando pela cana de açúcar, mineração e chegando até o café deixaram este fato patente. A partir da diferença do tamanho de Portugal e de sua população, em relação ao território e população brasileira, há aqueles que sugerem que a maior matéria prima do Brasil tenha sido o ouro vermelho, aquele que é extraído da mão-de-obra escrava (Hemming, 1978), em um primeiro momento, e da mãode-obra barata no presente. Aliás, se nos detivermos na análise do nome Brasil, constataremos que ele foi dado pelos portugueses à terra descoberta graças à grandiosa quantidade de pau-brasil aqui encontrada, deixando no próprio nome do país a marca perpétua da exploração (Calligaris, 1991).

Um ponto conseqüente do citado acima, mas igualmente importante a se destacar é o fato de que, ao longo de nossa formação histórica, de modo geral, as iniciativas políticas tomadas não tinham como preocupação as necessidades locais de desenvolvimento, mas o objetivo claro de facilitar a maximização da exploração de nossos recursos naturais (Prado Jr., 1948; Holanda, 1973; Faoro, 1976), não importando se para tanto deveriam ser implementadas feitorias, lati- 
fúndios ou dadas concessões de exploração. A criação de infra-estrutura local — estradas, ferrovias, vilas, aparelhos administrativos governamentais - até o início do século XX, em larga medida, deu-se para facilitar a exploração de nossos recursos naturais que seriam vendidos para a Europa. Além disso, os recursos advindos destas explorações ou foram concentrados nas mãos de uma elite, com raízes tipicamente européias e com certo desprezo pelo país, ou foram diretamente revertidos para os países europeus: tudo para a elite e sua metrópole e nada para o povo, eis o sentido claro de nossa formação histórico-social (Holanda, 1973; Faoro, 1976).

Tendo isso em vista, passaremos, a seguir, a analisar o Brasil nas figuras retóricas do colono e do colonizador desenvolvidas por Calligaris (1991). Na segunda parte do ensaio, mostrando como este traço está presente ao longo da formação nacional e, com o auxílio da discussão de Calligaris (1991), tentaremos argumentar que o estrangeirismo pode ser visto como catalisador da segregação, tanto entre pessoas como entre empresas, no mundo organizacional. Por derradeiro, faremos nossas considerações finais.

\section{'Brasil, o País que não Presta'}

A velha piadinha "Espera para ver a gentinha que eu vou pôr lá", referindo-se aos privilégios naturais do Brasil e à seu povo, parece ser, na verdade, a visão extremamente negativa do país, em comparação com uma admiração desmedida dos países do Primeiro Mundo, especialmente Estados Unidos e países europeus.

"Este país não tem jeito", ou a forma mais direta e indelicada "Este país não presta", são frases ouvidas nos táxis, nos botecos e nos salões. Um número muito grande de brasileiros orgulham-se de ter um passaporte estrangeiro, graças à benevolência de alguns países para com brasileiros descendentes de imigrantes dessas origens. Muitos brasileiros, enfim, emigraram, e provavelmente ainda emigram, para os Estados Unidos, Japão e Europa. No mundo organizacional, a emigração temporária para se civilizar é vista como indispensável tanto para acadêmicos como para executivos (Caldas e Wood, 1997).

Difícil imaginar um europeu dizendo coisa semelhante de seu país. Ele poderia afirmar que o governo não presta, mas nunca a sua terra (Calligaris, 1991). Também se dizia, tempos atrás, "o último que sair apaga a luz", coisa impensável nos lábios de cidadãos de outros países. O que estará por trás disto tudo, senão uma questão de identidade? 
Calligaris (1991) cria o neologismo UMtegração para tentar explicar o que se passa. Usa UMtegração e não integração, pois não falta patriotismo aos brasileiros, nem capacidade de convivência entre etnias diferentes, muito embora a elite seja invariavelmente, ou quase invariavelmente, branca ou que se vê como branca e o povo mulato, na maioria dos casos. Casa Grande e Senzala é, pois, hoje uma metáfora para explicar um Brasil de diferenças sociais enormes, marcadas na cor da pele.

Calligaris (1991) defende que há no Brasil uma dificuldade relativa ao UM, ao qual toda e qualquer nação refere aos seus filhos. Trata-se de uma dificuldade relativa à significação e à história que dizem respeito ao significante nacional.

É que falam em cada brasileiro um colonizador e um colono. São figuras retóricas, as figuras retóricas dominantes no discurso brasileiro. Colonizador e colono apresentam uma relação com a história, pois é ela que permite pensá-los; todavia não se trata de categorias sociais, nem psicológicas. É no discurso de cada brasileiro, que falam ou parecem falar, colonizador e colono (Calligaris, 1991).

O colonizador é aquele que veio para impor a sua língua materna a uma nova terra. Para a psicanálise, ela não é propriamente nem a língua, nem a língua falada pela mãe para a sua criança, nem a língua que cada um começou a falar. Ela é a língua em que o corpo materno aparece como impossível. Assim, não é uma língua natural, tampouco nacional. É uma língua singular, quiçá uma torre de Babel, em que cada pessoa institui o simbolismo de um pai que o aceite como filho, em troca de uma interdição do corpo materno. A língua responsável pela interdição, a língua que interdita, é a mesma que permite sonhar com o que foi interditado. Por essa razão, é a língua materna e não paterna. Para cada pessoa é a língua da estrutura simbólica que a faz sujeito, mas é igualmente a língua do gozo perdido por ser sujeito (Melman apud Calligaris, 1991).

Quem veio impor a potência paterna, veio, ao mesmo tempo, demonstrar a potência do pai. A língua do pai, que podia gozar o corpo da mãe, vem demonstrar que pode gozar outro corpo que não o materno, longe do pai. Talvez a interdição diga respeito só à mãe pátria e o novo corpo esteja livre para o gozo do filho, do colonizador.

Não há diferença notável na língua portuguesa entre colonizador e explorador. Ele é o primeiro a conhecer a terra, mas diferentemente das demais línguas, ou pelo menos das mais conhecidas entre os latinos, ele também é o primeiro a arrancar seus recursos (Calligaris, 1991), como vimos no início deste ensaio. Essa ambigüidade de definição permite ver o colonizador como alguém que sacode o Brasil como se pode sacudir uma mulher que está sendo possuída. É o 
que grita "goza Brasil", ao mesmo tempo que aguarda o momento do seu próprio gozo, quando esgotado, o país se acaba, comprovando a potência do estuprador.

As piadas sobre portugueses no Brasil, que parecem extremamente antigas, e que normalmente falam de uma pretensa pouca inteligência daqueles que são semelhantes ao que existe entre outros povos, como por exemplo os franceses vêem os belgas. O que torna porém o nosso caso único é o fato de a maioria dos brasileiros ser descendente de portugueses; porém os portugueses são aqueles que não sabem gozar um corpo não proibido, já que preferiram ficar.

Calligaris (1991) prossegue colocando que essa possibilidade de gozar ilimitadamente, pelo menos para os padrões de outros povos, "na terra em que tudo dá", torna os brasileiros, tão corteses na maior parte das vezes, também arrogantes. Muitas situações os levam a isso, como mostra a desagradabilíssima pergunta "Você sabe com que está falando?", que aproximadamente significa eu (e minha família) soube gozar melhor do que você, ou eu (e minha família) tenho mais direito de gozar do que você.

O colonizador, de acordo com o autor, "feliz" e "poderoso", semelhante a um maníaco depressivo, em sua fase de mania, também tem mais tristezas, ou o seu lado "depressivo". O corpo que estreita em suas mãos e que por vezes sacode é um corpo no qual não recaem interdições. Além disso, é um corpo que goza, isto é, que responde ao seu "desejo" e a sua ação. Ele sabe que não é esse corpo que queria, mas o que deixou um dia, ou que alguém que veio antes podia ter deixado. Ele sonha com outro corpo, mais belo, mais nobre que este que lhe é acessível, o corpo materno que ele mal conhece, e que na sua imaginação é pleno de virtudes e sem vícios, a exemplo de Ciranda da Bailarina, de Chico Buarque e Edu Lobo, que não tem qualquer coisa feia ou mal vista.

Ele queria fazer gozar o corpo interditado. O Brasil deve ser explorado, esgotado até o fim, sem dó nem piedade, uma espécie de manequim nas mãos do colonizador, algo que só faz lembrar muito palidamente o único corpo que realmente contava, o corpo interditado da mãe terra. Apropriar-se do país, demostrando toda a sua potência; mas, ao mesmo tempo, constata o fracasso dessa apropriação. A potência não é sua, exerce-a em nome do pai, num corpo que não é também o da mãe pátria. O colonizador veio "fazer a América", como se dizia no passado. Em outras palavras, numa metáfora sexual, ele veio "gozar a América"; entretanto não era a América que ele queria fazer gozar, mas outras tantas pátrias de referência, como a França, Grã-Bretanha, Alemanha, Estados Unidos etc. Não é a origem que conta, mas o valor da referência.

O Brasil jamais poderá gozar da forma que os outros imaginariamente gozam, e o Brasil não pode ser a França ou os Estados Unidos. O mesmo se dá com a gestão 
de pessoas que dirige brasileiros e não norte-americanos ou franceses. Como o colonizador não se conforma com isso, ele imagina que tem algo a cobrar permanentemente do país, do seu povo, e também de suas autoridades; porém, em vez de cobrança, o que se ouve é "Este país não tem jeito", "Este país não presta".

Já o colono é aquele que, tendo abandonado sua língua materna, viajou para outra língua. Isto vale para todos, incluindo os portugueses, que foram os primeiros a chegar e continuaram a chegar, mas não tanto por essas razões históricas, já que ser colono ou colonizador são na verdade posições subjetivas. Não se trata de alguém atrasado que espera participar do festim do colonizador. Adere à nova língua não para ter acesso a um corpo materno finalmente permissivo. "Ele é diferente porque procura um nome, um novo pai que estabeleça limites e o reconheça". O pai que o deixou partir não foi na verdade seu pai.

Calligaris (1991, p. 20) relata que

"existe em Bento Gonçalves, um admirável museu da imigração italiana. Nele está exposto, entre outras coisas, o passaporte de um imigrante italiano, vindo ao Brasil com a mulher grávida e os filhos pequenos; como se fosse, o passaporte da época era um salvo conduto, uma simples folha de papel sem imagens, na qual o Rei da Itália autoriza só esta viagem, e só esta destinação. O nosso imigrante, provavelmente analfabeto, talvez neste começo de século encontrasse pela primeira vez, na ata de seu passaporte, alguma forma de reconhecimento de sua existência de sua consistência simbólica e jurídica. Deixar a sua língua materna produzia milagrosamente um documento no qual, por ele ser nomeado, a sua dignidade humana era reconhecida".

A divina Ordem e Progresso foi escrita pelo colono, uma interdição paterna que fizesse dele um sujeito. O colono também pode dizer, mais dramaticamente, este país não presta, sancionando o fracasso da UMtegração: o país não soube ser pai, o colono não foi assujeitado pelo UM nacional. O colono não encontra um quadro nacional que the outorgue a cidadania. Quando um atravessador the apresenta o novo pai, ele descobre a farsa: o pai prometido também está atrás de um pai e, pelo que esse pode representar, descobre também que há um colonizador por trás do pai.

Quando emigra, o brasileiro tem dificuldade em voltar. A dificuldade é cultural. Como exibir diante de uma língua que não o reconhecia, outra que também não o reconhece. Colono e colonizador parecem suspensos em meio a uma viagem. Há sempre a esperança de encontrar uma terra a mais, se não houver mais o que explorar ou se algum UM nacional não me fizer cidadão. Os barcos não foram queimados (Calligaris, 1991). 
Num esforço comovente, o brasileiro procura encontrar um norte cultural no escravo, terceira dimensão de seu discurso; todavia o escravo também não é uma fala integradora, dada a natureza de Casa Grande e Senzala da cultura brasileira, distâncias sociais enormes. Parece que a busca de UMtegração caracteriza o Brasil e será por muito tempo o traço fundamental, a cara do país que não consegue ser mãe nem pai.

Tendo por base a discussão aqui apresentada, analisaremos a valorização do estrangeiro em nossa cultura e como tal valorização está presente no mundo organizacional, exercendo um papel de segregação entre pessoas e entre empresas.

\section{A Valorizaçāo do Estrangeiro (Estrangeirismo) como Segregaçāo}

Escrevendo uma crônica a partir de um conto do vigário sofrido, o articulista Marcelo Coelho (2000, p. 5), do jornal Folha de São Paulo, afirmou: "temos a alegria de não sermos xenófobos. $\mathrm{O}$ estrangeiro sempre nos parece superior: mais culto, mais civilizado. Nacionalizamos a patifaria. Se o brasileiro, por definição, é o malandro, aquele que quer levar vantagem em tudo, decorre mais ou menos logicamente que o gringo é honesto e ingênuo. Sentimos orgulho, portanto (eu senti) ao sermos ingênuos. Curiosa a forma de nacionalismo, a que se expressa em submissão; mas é assim que funcionamos, a meu ver".

Esta passagem do texto deixa claro o que entendemos por estrangeirismo: a valorização do que é estrangeiro, menosprezando o que é brasileiro, ou seja, como o próprio articulista nos mostra que aconteceu com ele: sentir orgulho de se identificar com o estrangeiro e, assim, negar sua brasilidade. Tal fato parece estar presente pelo menos em todos os brasileiros bem nascidos, chegando ao ponto do nacionalista e a defesa do tipicamente brasileiro, em nosso país, serem estereotipados com cores de ridículo, a exemplo de Policarpo Quaresma. Também podemos ver isso como uma caraterística típica das figuras retóricas do colonizador e do colono. O primeiro não valoriza o país pelo fato de não ser aqui a terra que ele queria fazer gozar, ao passo que o segundo não o faz por querer ser reconhecido e não o ser por este país, já que "não existe pecado do lado de baixo do Equador".

Faoro (1976) nos aponta que no período de nossa colonização o aparelho para gerir a colônia surgiu antes da população e que em nossa peculiaridade os ordenamentos jurídicos sempre foram concebidos com o intuito de criar a realidade e não de regulamentá-la; "as vilas se criaram antes da povoação, a organização administrativa precedia ao fluxo das populações. Prática do modelo de ação do 
estamento, repetido no Império e na República: criação da realidade pela lei, pelo regulamento [...] a América seria um reino a moldar, na forma dos padrões ultramarinos, não um mundo a criar" (Faoro, 1976, p. 121).

Prado Jr. (1948, p. 345) concorda com Faoro (1976) expondo: “o poder não brotou no íntimo da sociedade brasileira, incapaz de tal criação, mas the foi imposto do exterior". Ainda nesta linha, Holanda (1973, p. 119) defende que os portugueses "trouxeram de terras estranhas um sistema complexo e acabado de preceitos, sem saber até que ponto se ajustavam às condições de vida brasileira $\mathrm{e}$ sem cogitar das mudanças que tais condições lhe imporiam".

Assim, o ímpeto de exploração metropolitano no período colonial fez com que o reino português evitasse o desenvolvimento do país enquanto tal e não levasse em conta as peculiaridades nacionais na implementação das estruturas administrativas, sociais e econômicas. Ele tentou sempre impor seu modo de vida e suas estruturas governamentais. A bem da verdade, como já vimos, o Brasil era visto como uma terra a ser explorada e não como terra a ser desenvolvida. O que se destaca é o fato da criação da realidade pela lei estrangeira ter por objetivo dominar a população que aqui estava, fornecendo-lhe fórmulas prontas e acabadas de como deveria portar-se; os membros da elite nacional eram os defensores dos interesses da metrópole no país; portanto a metrópole explorou e pretendia dominar a colônia; para tanto moldou-a e geriu-a a sua imagem e semelhança (Holanda, 1973; Faoro, 1976).

Posteriormente, a Independência do país se deu e a própria palavra 'Independência' parecia sugerir que o país começaria a caminhar por si só; entretanto com ela o regime colonial e todos os seus ranços não se extinguiram, mas modernizaram-se. O que ocorreu, de fato, foi uma reorganização dos papéis, já que a figura da metrópole foi trocada pela do Imperador Dom Pedro e seu estamento; no auge da centralização imperial, o país continuou a sofrer um processo de europeização, trocando, entretanto, Portugal pela Grã-Bretanha. Iniciou-se um progresso consciente de desenvolvimento calcado nos moldes britânicos. A elite nacional que tinha por guia os lusitanos passou a ter os ingleses. Ao Estado coube o papel de intermediar o impacto estrangeiro. $\mathrm{O}$ Tesouro queria adequar o país ao mundo moderno, impondo-lhe maior ritmo de progresso. O sistema tributário aduaneiro privilegiava a entrada de produtos britânicos. A economia brasileira transformou-se em um apêndice da britânica (Faoro, 1976).

Não pensemos que a adoção destes modos de sociedades desenvolvidas, impondo os interesses de uma elite minoritária sobre os interesses da população local ficaram restritos aos tempos de Brasil Colônia e Império. Dando continuidade ao seu argumento Faoro (1976), em sua fantástica análise dos Donos do Poder, mostra-nos que ao longo de nossa história testemunhamos a valorização 
pelos donos do poder local da adoção de modos de vida estrangeiros, primordialmente dos países tidos como desenvolvidos para cada época histórica (Portugal, Grã-Bretanha, França) em nossa sociedade, a fim de que ela pudesse articular-se com o mundo desenvolvido, tido como o ponto de chegada desejado para nosso país. Baseado em Celso Furtado, Caldas (1997) argumenta que o nosso processo de industrialização foi realizado para atender à mundialização da economia norte-americana. Tal processo criou padrões de consumo drasticamente elevados para uma pequena parcela da população, mantendo a distância entre as camadas sociais. Neste cenário, Barbosa (1999), analisando a maneira com que os brasileiros lidam com a meritocracia, contrapondo nossa sociedade aos Estados Unidos e ao Japão, e buscando as relações entre antropologia e os estudos organizacionais, aponta que a sociedade brasileira sempre teve outros preferenciais e que desde a Segunda Guerra Mundial até os dias de hoje os Estados Unidos se encontram neste lugar, servindo de norte para as nossas discussões domésticas sobre modernidade, cidadania, indivíduo, liberdade de mercado etc. Hoje, a ideologia que desponta como geral é: o que funciona nos Estados Unidos, deve (precisa) funcionar no Brasil.

Tendo isso em vista, percebemos a pertinência das figuras retóricas desenvolvidas por Calligaris (1991) apresentadas no item anterior e a complementaridade de sua análise com a que estamos desenvolvendo neste item. Aqui podemos ver que a terra brasileira e o seu povo sempre foram vistos como algo que deveria ser explorado ao máximo, terra para a extração do ouro vermelho, algo que deveria gozar infinitamente para satisfazer os desejos do frustrado colonizador; a elite nacional continua a agir como tal, querendo tirar mais e mais do país e de seu povo, perpetuando-se a natureza Casa Grande e Senzala de nossa cultura. Como mostramos acima, tanto o colonizador como o colono estão presentes imaginariamente em cada brasileiro. $\mathrm{Na}$ análise histórico-cultural, a figura do colono também encontra seu espaço, já que ao longo de nossa história se evitou ao máximo o reconhecimento das características locais para o desenvolvimento do país por si só, deixando claro que o colono não consegue, historicamente, seu almejado reconhecimento. Analisando-se, portanto, a formação nacional e o seu desenvolvimento histórico-cultural, pode-se perceber a pertinência das figuras retóricas de Calligaris (1991) e a sua importância na compreensão de nossa cultura.

Um exemplo interessante da valorização e adoção de modos de vida importados nos é dado por Sevcenko (1985), relatando uma pesquisa que fez sobre o Rio de Janeiro no período de 1900 até 1920. Segundo o autor, pelos idos de 1900, o Rio pretendia tornar-se uma grande capital burguesa, para poder receber as mercadorias européias, seus negociantes, capitalistas e, conseqüentemente, seus capitais. O porto do Rio havia-se transformado no terceiro em volume da América. 
O governo local e a elite achavam que a cidade e a sua população, em suas feições tradicionais, eram um entrave para este fato, pois tinham vergonha de sua aparência subdesenvolvida e achavam que os europeus não iriam sentir-se em casa. Tendo por objetivo mudar a feição do local, reurbanizou-se a cidade, jogando todos os pobres que viviam no centro para os morros, e acentuou-se um estilo europeu de vida. Sevcenko (1985, p. 47) nos relata algumas cenas decorrentes deste fato: "as moças não sabiam como usar as roupas européias. Quem sabia disso eram as prostitutas européias, francesas em particular. Então o five-o-clocktea era o momento social da alta burguesia carioca com as prostitutas francesas". Além das prostitutas ensinando bons modos, tivemos a prática espúria de esconder a dimensão negra brasileira: "ninguém tomava banho de mar. E todos, de manhã cedo, era um hábito entre os mais jovens, entre os nubentes, tomavam um copo de vinagre em dejejum, para provocar um embranquecimento da pele, uma palidez meio esverdeada que era tida como de bom gosto" (Sevcenko, 1985, p. 48).

Por outras vias, Riggs (1963) e Guerreiro Ramos (1983) demonstram que a adoção de modelos políticos e modos de vida estrangeiros surgem com o intuito de fazer com que as sociedades em vias de desenvolvimento possam articularse, por meio de uma aparente modernidade, com as sociedades desenvolvidas das quais as primeiras são dependentes. No caso brasileiro, como acabamos de ver, esta dependência quer seja no período colonial, quer seja em nossa industrialização, não se deu por meio de ganho mútuo, mas através da exploração dos recursos naturais locais e/ou do nosso mercado para o benefício do estrangeiro, ou seja, configurou-se como forma de dominação e exploração local, voltada para fora, perpetuando o sentido exploratório da colonização.

Ainda mais, a valorização destes modos e modelos, além de servir como forma de se articular com o estrangeiro desenvolvido, serviu como fator de diferenciação da elite perante o povo em geral, já que ela se juntou às metrópoles estrangeiras para extrair ao máximo os frutos da nossa terra, como muito bem nos mostraram Prado Jr. (1948), Freyre (1963), Holanda (1973) e Faoro (1976). Spink (1994), tendo por base Faoro (1976), afirmou que o Brasil vem sendo palco de sucessivas imposições de modelos modernizadores, cuja função é sempre saltar etapas imaginárias em grandes e populíssimos momentos de progresso nacional; entretanto a modernização imposta pelas elites deixa a maioria da população à margem de seus benefícios sociais, sendo que tais modernizações sempre favoreceram os interesses das elites em primeiro plano (Spink, 1994), ou seja, a modernização dá frutos para os donos do poder que assim perpetuam sua posição na pirâmide social.

$\mathrm{O}$ interessante desta junção entre elite e estrangeiros é que ela fazia com que a primeira tentasse subjugar a população local, ao mesmo tempo que era dependente dos países com os quais queria articular-se. 
Além disso, utilizando as figuras retóricas de Calligaris (1991) para entender a preferência pelo estrangeiro, o que parece estar subjacente é que, adotando estes modelos e modos de vida estrangeiros, o colonizador tenta fazer com que esta terra fique parecida com a sua terra de referência, ou seja, busca criar uma identidade entre a sua terra original idealizada e a terra em que vive; mas sabe, ao mesmo tempo, que o Brasil nunca será como ela.

Assim, o que significa usar roupas européias no tórrido clima carioca, não ir à praia e beber vinagre para esconder a dimensão negra brasileira? Significa negar a própria origem, negar que temos fortes influências indígenas e negras em nossa formação histórica, ou seja, negar que muitos de nossos bisavós, muito provavelmente, foram escravos, trabalharam duro e foram pobres; significa negar que pertencemos a esta terra que não tem interdição e fazemos gozar, voltando a nossa fase de depressão. $\mathrm{O}$ que parece estar por trás disso é o fato de que ser brasileiro é sinônimo de ser escravo, caipira ou jeca tatu; em suma: ser pobre e ignorante. Prado Jr. (1948) já defendia que, em nosso país, a discriminação entre as pessoas não se dá de forma marcante na diferença étnica, como nos Estados Unidos, mas pela diferença de dinheiro e poder, ou seja, de posição social; de quem mora na casa grande contra quem mora na senzala. Freyre (1963) já apontava que o binômio Casa Grande e Senzala está notoriamente inscrito em nossa cultura.

Por meio das imagens mostradas por Sevcenko (1985), podemos perceber algo que acompanha o país desde as suas origens: a elite nacional tem vergonha de ser brasileira e menospreza sobremaneira o que é nacional, buscando no exterior, na negação de sua brasilidade, a sua identidade. A personagem Caco Antibes do programa humorístico Sai de Baixo fornece-nos uma caricatura deste brasileiro que se identifica com o estrangeiro, tem a sua identidade como se fosse estrangeiro e que "odeia pobre", a despeito de ser um deles.

Como estas características estariam, então, presentes tanto nos estudos organizacionais como na prática das organizações brasileiras?

\section{Estrangeirismo e Organizações}

Como vimos, a estruturação e a formação do Estado no Brasil foram embasadas nos modelos europeus. Tais estruturas foram transportadas diretamente da Europa sem saber como se ajustariam às nossas peculiaridades (Holanda, 1973). 
Mas isso não parou por aí. Quando se deu o desenvolvimento industrial, ele ocorreu calcado na experiência das nações ocidentais mais avançadas, resultando deste fato a filosofia que direcionou a criação das escolas de administração nacionais. $\mathrm{Na}$ época da sua fundação e desenvolvimento, as instituições norteamericanas tiveram papel fundamental tanto na seleção dos primeiros professores quanto na metodologia de ensino adotada (Serva, 1990).

A partir da análise do papel específico da ideologia gerencial no desenvolvimento do sistema fabril em sua fase inicial, em nosso país, elaborada por Pena, Serva (1992) mostra que a importação de metodologias e modelos administrativos foi extremamente importante na solidificação da ideologia burguesa industrial naquela época, gerando a identidade da burguesia industrial de então. Percebemos aqui o papel da adoção de modelos estrangeiros na solidificação da identidade da elite.

A criação das escolas de administração teve papel fundamental na institucionalização da importação desses modelos e metodologias. Em seguida, presenciou-se uma rede de diversos atores sociais, tais como empresas de treinamento, consultorias etc, que deram continuidade a este processo, sem que as escolas de administração tenham perdido o seu papel fundamental na propagação de metodologias e modelos administrativos importados (Serva, 1992) .

Neste cenário, Serva (1992) defende que estes métodos e/ou modelos assumiram uma dimensão mitológica, já que tanto os praticantes como aqueles que ensinam administração acreditam que devem sempre seguir os modelos estrangeiros e defendem que as organizações somente conseguirão desenvolver-se, implementando os modelos modernos gestados no Primeiro Mundo; caso contrário, ficarão obsoletas. Notamos aqui a presença do estrangeirismo como catalisador da adoção destes modelos, já que, como vimos no início deste item, historicamente o ser moderno e de boa qualidade está, em nosso país, associado com o ser estrangeiro.

Tais mitos são forjados, surgem para produzir modas e criar uma ansiedade permanente nos administradores pelo que de mais novo foi produzido no exterior (Serva, 1992). A presença destes modismos gerenciais fica patente, quando vemos a realidade das organizações. Qual empresa brasileira escapou de um processo de reengenharia no início da década passada? E da qualidade total ?(1) $^{(1)}$

A valorização do estrangeiro e a adoção de modelos e teorias administrativas estrangeiras não ficaram circunscritas ao lado prático da administração. Bertero e Keinert (1994), analisando 32 anos (1961 a 1993) de artigos publicados na área de análise organizacional, constataram que consumimos, repetimos e divulgamos idéias produzidas fora do país, principalmente provenientes dos Estados 
Unidos, ou seja, a análise organizacional brasileira limita-se a reproduzir de maneira didática o que foi produzido no exterior. Corroborando esta análise, Vergara e Carvalho (1995) comprovam que, na amostra que analisaram, 78,3\% das referências nos artigos da análise organizacional em nosso país são estrangeiras, primordialmente norte-americanas, francesas e britânicas. Além disso, de acordo com os autores, o motivo para a utilização destes referenciais não se dá devido à adequação deles à nossa realidade, mas pela influência que tais referenciais têm na formação dos autores brasileiros. Assim, tanto Bertero e Keinert (1994) quanto Vergara e Carvalho (1995) constatam não haver uma análise organizacional propriamente brasileira.

Examinando as implicações organizacionais da fixação brasileira na figura do estrangeiro, Caldas (1997) demonstra que, de fato, "santo de casa não faz milagre", quando se trata de administração no Brasil. Dando força a todas as análises descritas acima, Caldas (1997) defende que este comportamento está institucionalizado entre nós, e a educação (escolas de administração), os profissionais (consultores, executivos, conferencistas, palestrantes) e os próprios acadêmicos funcionam como agentes propagadores disso. Além do mais, a aprovação dos indivíduos no mundo organizacional depende do quanto eles mostram comungar das fontes de vanguarda estrangeiras, primordialmente americanas (Caldas, 1997), ou melhor, quanto mais aceitamos e propagamos o importado, mais parecemos civilizados (Caldas e Wood Jr., 1997). Assim, um intercâmbio, um MBA, uma expatriação, um doutorado ou pós-doutorado em uma universidade estrangeira aparece para nós como a melhor maneira de legitimar o executivo ou acadêmico em nosso meio, ou seja, a identidade de moderno está relacionada com repetir e implementar modelos e teorias gerados fora do país.

Desta maneira, quando falamos do mundo dos gestores no Brasil, há uma valorização extrema de modelos organizacionais, metodologias e teorias gerados alhures, não havendo preocupação com a pertinência (funcional) desses modelos à nossa realidade. $\mathrm{O}$ que há é uma preocupação nítida em se manter moderno, manter-se em contato com o mundo, fazendo com que nossa análise organizacional e nossa administração se desenvolvam a partir destes referenciais importados.

Quando colocamos o foco especificamente no mundo empresarial, notamos que se gastam milhões de reais anualmente com a adoção de metodologias e modelos de gestão que não são adequados à nossa realidade. Tais referenciais, no mais das vezes, não estão adequados às nossas peculiaridades histórico-sociais, já que não foram concebidos para elas. Nossa temática não é apropriada para a nossa realidade (Serva, 1990, 1992; Caldas, 1997). A maioria dos modelos importados, nas organizações, são implementados "para inglês ver", causam 
frustração ou têm de ser adaptados de maneira criativa (Caldas e Wood Jr., 1997). Até este ponto todas as análises do estrangeirismo no mundo organizacional são unânimes. Partindo de um ponto de vista ou de outro, elas sempre chegam aqui: temos enorme simpatia pelo que é gerado no exterior; estes modelos gerados alhures muitas vezes não condizem com a nossa realidade; precisamos mudar isso, e começar a levar nossa peculiaridade em conta etc. Tais análises não deram conta do papel de segregação que a valorização do estrangeiro desempenha em um país com um significante hiato entre as camadas socais.

Conforme analisado anteriormente, a idéia de seguir o estrangeiro para não ficar atrasado e poder se articular com ele está presente ao longo de nossa formação histórico-social, em nosso imaginário por meio das figuras retóricas do colono e do colonizador e funcionou como uma forma de diferenciar a elite dos demais, gerando a dependência e a exploração do nosso país. Mais uma vez, se destaca o papel paradoxal da elite que, por um lado, tenta subjugar a população local e, por outro, cria a sua identidade, a partir do referencial externo e, para isso, se obriga a seguir tais ditames, subjugada por eles.

Somente podem "comungar da fonte da vanguarda estrangeira", e assim, ser "civilizado e moderno" aqueles que estudaram em boas escolas, tiveram a possibilidade de morar no exterior (Europa ou Estados Unidos), ou seja, aqueles que possuem boas condições sociofinanceiras, uma elite enfim.

Quando falamos de organizações, o fato se repete. Somente as grandes empresas têm condições de implementar estes modismos ou mitos, já que somente elas têm condições de pagar as consultorias que implementam "estas maravilhas da gestão americana"; somente elas podem dar-se ao luxo de implementar modelos organizacionais "para inglês ver", ou seja, somente uma elite, tanto de empresas como de pessoas, pode ser moderna em nosso país.

Assim, dentro do mundo organizacional, seguindo a cultura de nosso país, o estrangeirismo funciona como forma de dar identidade à elite, tanto de pessoas como de empresas, e segregar os demais, além de dificultar que encontremos soluções próprias para os nossos problemas, que haja um desenvolvimento de modelos de gestão tipicamente nacionais, que levem em conta nossas especificidades na teorização e análise organizacional.

Se fizermos uma analogia com o modelo elaborado por Enriquez (1987), a respeito do controle sobre o pensar nas organizações, um dos elementos do triplo controle exercido (corpo, pensar e psique), veremos algumas coisas interessantes. Apesar de a organização pressionar a padronização do pensar, Enriquez (1987, p. 29) aponta que há uma contradição curiosa, pois ao mesmo tempo que se apela para adesão total do pensar, há a demanda pela criatividade e inovação: 
"o mais integrado, o mais adaptado e o mais conformado (a essa ideologia) raramente é o mais eficaz [...] mas essa contradição permite manter os colaboradores em um estado de culpabilidade permanente (nunca é suficientemente conformado, nem suficientemente criativo)", fortalecendo o controle organizacional. Da mesma forma a idealização dos modelos estrangeiros funcionaria para o estado de culpabilidade das empresas nacionais: nem somos tão adequados ao novo discurso gerencial, nem suficientemente criativos para enfrentar os novos desafios organizacionais.

O estrangeirismo, portanto, auxilia a perpetuar nosso papel de consumidores de metodologias e idéias geradas no exterior; nossa dependência e a segregação de uma elite dos demais têm um claro papel na perpetuação das relações de poder, de não permitir a mobilidade entre pessoas e entre empresas, auxiliando na perpetuação da Casa Grande e Senzala como traço cultural brasileiro, pelo menos dentro do mundo das organizações.

\section{Considerações Finais}

Antes de mais nada, cumpre dizer que não somos xenófobos que pretendem excluir totalmente a participação dos estrangeiros e seus modelos em nosso país e culpá-los por todos os nossos problemas sociais. Tampouco achamos que o estrangeirismo exerça papel fundamental na segregação das pessoas e na perpetuação das desigualdades brasileiras como um todo, e no mundo organizacional, em particular. Ele é somente mais um fator; agora vem o mais importante: não estamos tratando do estrangeiro em si, mas do imaginário dos gestores em relação a eles.

Neste ensaio, primeiramente discutimos a cultura brasileira, a partir da leitura de Calligaris (1991), que para tanto desenvolveu as figuras retóricas do colono e do colonizador. Ambos dizem a frase "este país não presta" em conotações distintas. O colono a diz por não ter sido interditado (reconhecido) pelo país, e o colonizador por não ser esta a terra que ele queria fazer gozar. A importância desta análise está em nos mostrar que todos nós brasileiros, imaginariamente, temos problema com a questão do UM nacional e que buscamos valorizar o estrangeiro para dirimir este problema. Além disso, ela serviu para mostrar como o estrangeirismo está inserido nos indivíduos brasileiros. Em nossa segunda análise, complementar a primeira, fizemos a genealogia do estrangeirismo, a partir dos traços histórico-culturais de nosso país. Por fim, mostramos como o estrangeirismo assume uma faceta de segregação no mundo organizacional em geral e na gestão de pessoas em particular. 
O que pretendíamos neste ensaio é chamar a atenção para a faceta de segregação que o estrangeirismo pode exercer e que muitas vezes fica obscurecida atrás de uma pretensa busca pela modernidade. Aliás, a modernidade, como mostramos, funcionou e funciona como uma ideologia que mascara a segregação que ela impõe.

A partir daí, configura-se como fundamental tentar desenvolver uma análise e uma prática organizacional que leve um pouco mais em conta nossa realidade, que as contribuições vindas de fontes estrangeiras sirvam para auxiliar este fim e não deixá-lo cada vez mais distante, dando maior significado para a teoria e a prática organizacional e administrativa que se ensinam e se aplicam neste país, já que estariam mais adequadas à sua realidade.

Este propósito já foi destacado e ressaltado por Guerreiro Ramos (1983) há algum tempo; pouco, muito pouco tem sido feito para operacionalizar isso. A pergunta que resta é: A quem interessa o estrangeirismo, ou melhor, interessa a alguém ter uma teoria das organizações que leve em conta nossa cultura?

\section{Nota}

${ }^{1}$ Wood Jr. (1996) apresenta uma análise interessante a respeito destes modismos na administração.

\section{REFERÉNCIAS BibLIOGRÁfICAS}

\section{ALCADIPANI, R.}

Formalismo e jeitinho brasileiro à luz da gestão de microempresas. In: $50^{\mathrm{a}}$ REUNIÃO DA SBPC - $5^{\mathrm{a}}$ JORNADA DE INICIAÇÃO CIENTÍFICA (1997: Natal). Anais... Natal: SBPC, 1997.

\section{BARBOSA, L.}

Ideologia e meritocracia. 2. ed. Rio de Janeiro: Editora da FGV, 1999.
BARROS, B.;

PRATES, M.

$O$ estilo brasileiro de administrar. São Paulo: Atlas, 1996.

BERTERO, C. O.; KEINERT, T.

A evolução da análise organizacional no Brasil (1961-1993). Revista de Administração de Empresas, v. 34, n. 3, p. 81-90, 1994. 
BORGES DE FREITAS, A.

Traços culturais para uma análise organizacional. In: PRESTES MOTTA, F. C.; CALDAS, M. Cultura organizacional e cultura brasilera. São Paulo: Atlas, 1997.

BRESLER, R.

Roupa surrada e o pai: etnografia em uma marcenaria. In: PRESTES MOTTA, F. C.; CALDAS, M. Cultura organizacional e cultura brasilera. São Paulo: Atlas, 1997.

\section{CALDAS, $\mathrm{M}$.}

Santo de casa não faz milagre: condicionamentos nacionais e implicações organizacionais pela figura do 'estrangeiro'. In: PRESTES MOTTA, F. C.; CALDAS, M. Cultura organizacional e cultura brasilera. São Paulo: Atlas, 1997.

CALDAS, M.;

WOOD JR., T.

'For the english to see': the importation of managerial technology in late $20^{\text {th }}$ century Brazil. Organization, v. 4, n. 4, p. 517-534, 1997.

CALLIGARIS, C.

Hello Brasil! São Paulo: Escuta, 1991.
CÂNDIDO, A.

Introdução. In: HOLANDA, S. B. Raízes do Brasil. Rio de Janeiro: Editora José Olímpio, 1973.

COELHO, M.

O conto-do-vigário para brasileiro ver e cair. Folha de São Paulo, 19 jan. 2000. Folha Ilustrada, p. 5-8.

COLBARI, A.

Imagens familiares nas organizações. In: DAVEL, E.; VASCONCELOS, J. (Orgs.). 'Recursos' humanos e subjetividade. Petrópolis: Vozes, 1995.

costa, A.

Cultura brasileira e organização cordial: ensaio sobre a Gaviões da Fiel. In: PRESTES MOTTA, F. C.; CALDAS, M. Cultura organizacional e cultura brasilera. São Paulo: Atlas, 1997.

DAMATTA, R.

Carnavais, malandros e heróis. Rio de Janeiro: Zahar, 1983.

DAVEL, E.;

VASCONCELOS, J.

Gerência e autoridade nas empresas brasileiras: uma reflexão histórica e empírica sobre a dimensão paterna nas relações de trabalho. In: PRESTES MOTTA, F. C.; CALDAS, M. Cultura organizacional e cultura brasilera. São Paulo: Atlas, 1997. 
ENRIQUEZ, E.

Les jeux du pouvoir et du désir dans l'entreprise. Paris: Desclée de Browner, 1997.

FAORO, R.

Os donos do poder - formação do patronato político brasileiro. 3. ed. Porto Alegre: Globo, 1976.

FISCHER, T.;

SANTOS, J.

O ‘capo' e o jogo do bicho - uma organização Paratodos. Organização e Sociedade, p. 121-129, 1995.

FREYRE, G.

Casa grande e senzala. 12. ed. Brasília: Ed. UnB, 1963.

GUERREIRO RAMOS, A. Administração e contexto brasileiro. 2. ed. Rio de Janeiro: FGV, 1983.

HEMMING, J.

Red gold - the conquest od the brazilian indians. London: MacMillan, 1978.

HOFSTEDE, G.

Culture's consequences: international differences in workrelated values. London: Sage Publications, 1984.
HOLANDA, S. B.

Raízes do Brasil. Rio de Janeiro: Editora José Olímpio, 1973.

PRADO JR., C.

Formação do Brasil contemporâneo. 3. ed. São Paulo: Editora Brasiliense, 1948.

PRESTES MOTTA, F. C.

Organização e poder. São Paulo: Atlas, 1986.

Cultura nacional e cultura organizacional. Revista da Escola Superior de Propaganda e Marketing, v. 2, n. 2, p. 32-47, 1995.

PRESTES MOTTA, F. C.;

CALDAS, $M$.

Cultura organizacional e cultura brasilera. São Paulo: Atlas, 1997.

RIBEIRO, D.

O povo brasileiro: a formação e o sentido do Brasil. São Paulo : Companhia das Letras, 1995.

RIGGS, G.

A ecologia da administração pública. Rio de Janeiro: Editora da FGV, 1963.

SERVA, M.

Contribuições para uma teoria organizacional brasileira. Revista de Administração Pública, v. 24, n. 2, p. 10-21, 1990. 
A importação de metodologias administrativas no Brasil - uma análise semiológica. Revista de Administração Pública, v. 26, n. 4, p. 128-144, 1992.

SEVCENKO, N.

As muralhas invisíveis da Babilônia moderna. Óculum Revista da Arquitetura, v. 1, ago. 1985.

SPINK, P.

Cidadania na organização e cidadania da organização: notas para a desconstrução de 'recursos humanos'. In: SPINK, M. J. A cidadania em construção. São Paulo: Cortez, 1994.
VERGARA, S.;

CARVALHO, D.

Nacionalidade dos autores referenciados na literatura sobre organizações. Revista Brasileira de Administração Contemporânea, v. 1, p. 170-188, 1995.

VERGARA, S.;

PALMEIRA, C.

A cultura brasileira revelada no barracão de uma escola de samba. In: PRESTES MOTTA, F. C.; CALDAS, M. Cultura organizacional e cultura brasilera. São Paulo: Atlas, 1997.

WOOD JR., T.

Gestão prêt-à-porter. Carta Capital, p. 76-78 set. 1996. 